\title{
STANDARD OF BEST PRACTICE: SIMULATION DESIGN
}

Lori Lioce, DNP, FNP-BC, CHSE, FAANP Simulation Coordinator and Clinical Associate Professor of Nursing, The University of Alabama in Huntsville, Huntsville, AL 35899 USA

Colleen H. Meakim, MSN, RN, CHSE, Director of Simulation and Learning Resource Center, Villanova University College of Nursing, Villanova, PA 19085, USA

Mary K. Fey, PhD, RN, CHSE. Program Manager, Center for Clinical and Academic Transitions, National League for Nursing, Washington DC, USA; Assistant Professor, University of Maryland School of Nursing, Baltimore, MD, USA

Joyce Victor Chmil, PhD, RN-BC, CHSE Assistant Professor of Nursing and Director, Clinical Nursing Simulation Center, Wilkes University, Wilkes-Barre, PA, 18766, USA

Bette Mariani, PhD, RN, Assistant Professor, Villanova University College of Nursing, Villanova, PA 19085, USA

Guillaume Alinier, PhD, MPhys, PGCert, MInstP, MIPEM, CPhys, SFHEA, Professor, University of Hertfordshire, Hatfield, AL10 9AB, UK and Hamad Medical Corporation Ambulance Service, Doha, Qatar P.O. Box 3050)

Acknowledgements: INACSL Board of Directors, Standards Committee 2014, Advisory Panel

\section{Standard Statement}

Simulation-based experiences should be purposefully designed to meet identified objectives.

\section{Rationale}

Standardized simulation design provides a framework for developing effective simulation-based experiences (SBEs). In this article, "Design" includes the best evidence from fields such as adult learning, education, instructional design, clinical standards of care, evaluation, and simulation. Purposeful simulation design promotes essential structure, process, and outcomes that are consistent with programmatic goals and/or institutional mission.

\section{Outcome(s)}

Effective healthcare simulation design facilitates consistent outcomes and strengthens the overall value of the simulation-based experience (SBE) in all settings.

\section{Criteria}

The sequence for developing a SBE may vary according to the objectives or desired outcomes. To achieve optimal outcomes, simulation design should consider the following elements:

1. Needs assessment

2. Measurable objectives

3. Format of simulation

4. Clinical scenario or case

5. Fidelity

6. Facilitator/Facilitative approach

7. $\quad$ Briefing

8. Debriefing and/or feedback

9. Evaluation

10. Participant preparation

\section{Criterion 1. Needs assessment}

Guideline Statement: A needs assessment provides the foundational evidence of the need for a welldesigned simulation. The results of the needs assessment guide the designer in developing an overarching goal or broad objective for the simulation, which in turn directs the designer in the development of simulation specific participant objectives. For specific information see INACSL Standards of Best Practice (SOBP): Standard III: Participant Objectives (2013). 
Guideline 1: A needs assessment may include analysis of:

- Underlying causes of a concern (e.g. root-cause or gap analysis)

- Strengths, weaknesses, opportunities, and threats (SWOT)

- Surveys of stakeholders, participants, clinicians, and educators

- Outcome data (e.g. from pilot testing; previous SBE's; aggregate healthcare data)

- Standards (e.g. certifying bodies, rules and regulations, protocols)

Guideline 2: The needs assessment includes an examination of knowledge, skills, attitudes and/or behaviors of individuals; organizational initiatives; systems analysis, clinical practice guidelines, quality improvement programs, and/or patient safety goals. The results of the assessment may assist designers to create innovative and interactive experiences, which address the identified needs in order to:

- Enhance curriculum in the classroom and/or clinical areas

- Provide opportunities for standardized clinical experiences

- Address competencies

- Improve quality of care and patient safety

- Improve readiness for clinical practice

\section{Criterion 2. Measurable Objectives}

Guideline Statement: Objectives are designed to address identified needs from a broad to specific scope. Prior to the development of the clinical scenario or case, measurable objectives are determined from the needs assessment to drive the design. The facilitator assumes responsibility for guiding the achievement of the full set of objectives throughout the SBE. For specific information see INACSL SOBP: Standard III: Participant Objectives (2013).

Guideline 1: Broad objectives reflect the purpose of the SBE and are related to organizational goals. Specific objectives are related to participant performance measures. Together they provide a blueprint for the simulation.

Guideline 2: During the design phase, a determination is made regarding which objectives will or will not be available to the participant(s) prior to the experience.

- Objectives that provide general information and context for the learner should be disclosed (e.g. Deliver care for a patient with heart failure).

- Participant performance measures should not be disclosed (e.g. critical element checklist).

\section{Criterion 3: Format of Simulation-Based Experience}

Guideline Statement: Selecting the format of the SBE is based on the needs assessment, resources, and broad objectives, taking into account targeted participants as well as the purpose, theory, and modality. The format of an SBE provides the structure and process and allows the designer to identify expected outcomes of the experience.

Guideline 1: Purpose, Theory, and Modality:

- The purpose of the SBE is to provide a formative and/or summative encounter.

- A theoretical and/or conceptual framework is chosen based on the identified purpose and the targeted participants (e.g. adult learners, inter-professional teams, etc.).

- The modality is the platform for the experience. Modalities can include mannequin based simulation, computer-based simulation, virtual reality, procedural simulation, simulated clinical immersion with patient simulators (mannequins) and/or standardized patients, and/or hybrid simulation,

Guideline 2: Structure: All SBEs include a starting point, structured participant activities, and an endpoint. The starting point represents the initial circumstances of the the patient or situation when the participants start their engagement in the SBE. Structured participant activities are designed for 
participant engagement. (e.g. a simulated case or an unfolding scenario, and/or psychomotor skill teaching/evaluation). The endpoint is the stage at which the SBE is expected to end, usually when expected learning outcomes have been demonstrated, time is exhausted, or the scenario can proceed no further.

\section{Criterion 4. Clinical Scenario or Case}

Guideline Statement: Development of the clinical scenario or case provides the context for the simulation experience. The designer should use a process that ensures quality and validity of the content, and maintains the reliability and standardization of objectives.

The clinical scenario or case story may include a situation and backstory, clinical progression and cues, time frames, script, and identification of critical actions:

Guideline 1: The Situation and Backstory provide a realistic starting point from which the structured participant(s') activity begins. The full picture of this context may be given verbally to the participants, found in the patient's file, or be revealed if requested through adequate inquiry on the part of participants.

Guideline 2: Clinical Progression and Cues provide a framework for the advancement of the clinical case or scenario in response to participant actions, including standardization of cues to guide the participant(s). These critical cues should be linked to performance measures and used to re-focus participants when they stray from the intended objectives. This can be done using cues provided to the participant(s) (e.g. verbal, visual, or other cues).

Guideline 3: Time Frames are established as part of the design to ensure there is reasonable time to achieve the objectives.

Guideline 4: The script of a scenario or case is developed for consistency and standardization to increase scenario repeatability/reliability. Unintentional variations from the planned dialogue may add distractions that could interfere with the learning objectives.

Guideline 5: Identification of Critical Actions/Performance Measures is required to evaluate achievement of scenario objectives. Each measure should be evidence-based. Use of subject matter experts will strengthen validity of the simulation scenario.

\section{Criterion 5. Fidelity}

Guideline Statement: Many types of fidelity should be considered to create the required perception of realism. This perception of reality allows participants to engage in a relevant manner. The design of the simulation is enhanced through attention to physical, conceptual, and psychological aspects of fidelity to contribute to the attainment of objectives.

Guideline 1: Physical fidelity relates to how realistically the physical context of the simulation-based activity replicates the actual environment in which the situation would occur in real life. Physical fidelity includes such factors as the patient(s), simulator, standardized patient, environment, equipment, embedded participants, and related props.

Guideline 2: Conceptual fidelity ensures that all elements of the scenario or case relate to each other in a realistic way so that the case makes sense as a whole to the learner(s) (e.g. vital signs are consistent with the diagnosis). To maximize conceptual fidelity, cases or scenarios should be reviewed by subject matter expert(s) and pilot-tested prior to use with learners.

Guideline 3: Psychological fidelity is maximized when the simulation environment mimics contextual elements found in clinical environments, e.g. an active voice for the patient(s) to allow realistic conversation, noise, distractions, family members, other health care team members, time pressure, and competing priorities. The higher the psychological fidelity the more realistically learners will engage in the experience and hence display their professional abilities and level of competence.

\section{Criterion 6. Facilitator/Facilitative approach


Guideline Statement: In the design phase, the facilitative approach is determined. The specific facilitation method is participant-centered and driven by the objectives, participant's knowledge/level of experience, and the expected outcomes. For the most effective outcomes, it is recommended for the facilitator to receive formal training in simulation-based pedagogy. The level of facilitator involvement is inversely proportional to the participant's knowledge, experience, and personal perspective (frame). The facilitative approach should be consistent among facilitators for each scenario, case, or SBE. For more specific information on facilitation or facilitator see INACSL Standards of Best Practice (INACSL SOBP): Standard IV: Facilitation and Standard V: Facilitator (2013).

\section{Criterion 7. Briefing}

Guideline Statement: Briefing is an integral part of the SBE. Briefing sets the stage for the SBE by identifying participant's expectations and may differ depending on the level of expertise of the participant(s) and theoretical framework. Briefing is structured, planned for consistency, and completed immediately prior to the scenario/case.

Guideline 1: Briefing activities include the establishment of an environment of integrity, trust, and respect. Briefing includes identification of expectations for the participant(s) and the facilitator(s). This includes establishment of ground rules and a fiction contract.

Guideline 2: Briefing should include orientation of the participant(s) to the space, equipment, simulator, roles (participants/facilitator/standardized patient), time allotment, objectives (general information and context, see Criterion 2), patient situation and limitations.

Guideline 3: A written or recorded briefing plan standardizes the process and content for each scenario/case.

\section{Criterion 8. Debriefing and/or Feedback}

Guideline Statement: In the design phase of the SBE, a debriefing or feedback method is identified. Debriefing and feedback are different, but both are critical elements that should be structured using best practices. Effective debriefing is enhanced by adequate training and preparation of the facilitator. Using a planned debriefing or feedback session enhances learning and contributes to the consistency of the SBE for participants and facilitators. In the case of a skills-based or testing simulation activity, debriefing may be replaced by feedback so the participants are guided to further improve or confirm their practice. For specific information see INACSL SOBP: Standard VI: The Debriefing Process (2013).

\section{Criterion 9. Evaluation}

Guideline Statement: In the design phase, evaluation processes are determined to ensure quality and effectiveness. Adoption of an evaluation framework guides selection/development of a valid tool that is used to measure outcomes. Participant evaluation may be formative, summative, and/or high-stakes. Methods of evaluation should be clear to the participant(s) prior to or at the onset of the simulation. The evaluation process includes an evaluation of the participant(s), facilitator(s), the SBE, the facility, and support team. Evaluation includes input from participants, peers, and stakeholders. These data are used to assist in evaluating the simulation program for quality process improvement; hence any evaluation needs to be followed up by action based on the results. For specific information see INACSL SOBP: Standard VII: Assessment and Evaluation (2013).

\section{Criterion 10. Participant preparation}

Guideline Statement: In the design phase, inclusion of participant preparation should be determined once all the elements of the SBE have been identified. Preparation is designed to promote the best possible opportunity for participants to successfully address the simulation objectives. The designer and facilitator are responsible for ensuring that preparatory activities address the knowledge, skills, attitudes, and behaviors that will be expected of the participants during the SBE. Preparation activities should support the 9/7/15 
participant(s) ability to achieve the objectives of the SBE and are completed in advance of the SBE briefing.

Guideline 1: Participants should be prepared with a basic understanding of the concepts related to the SBE. Preparation may include:

- Activities related to the content (e.g. reading assignments, coursework, didactic sessions, answering simulation specific questions, watching preparatory audiovisuals, completing a quiz, etc.)

- Information regarding codes of conduct, confidentiality, and expectations. For more information see INACSL SOBP Standard II: Professional Integrity of Participant(s) (2013).

\section{Design Templates}

A template may be selected to guide the evidence-based design and standardize the design process. A sample of templates is available at http://www.inacsl.org/i4a/pages/index.cfm?pageID=3407. 


\section{References}

Alinier, G. (2011). Developing high-fidelity health care simulation scenarios: A guide for educators and professionals. Simulation \& Gaming, 42(1), 9-26. . doi: 10.1177/1046878109355683

Anderson, J.M.; Aylor, M.E.; Leonard, D.T. (2008). Instructional design dogma: Creating planned learning experiences in simulation. Journal of Critical Care, 23, 595-602.

Barsuk, J. H., Cohen, E. R., Feinglass, J., McGaghie, W. C., \& Wayne, D. B. (2009). Use of SimulationBased Education to Reduce Catheter-Related Bloodstream Infections Simulation Catheter Training to Reduce Infections. Archives of internal medicine, 169(15), 1420-1423.

Draycott, T., Sibanda, T., Owen, L., Akande, V., Winter, C., Reading, S., \& Whitelaw, A. (2006). Does training in obstetric emergencies improve neonatal outcome?.BJOG: An International Journal of Obstetrics \& Gynaecology,113(2), 177-182.

Gore, T. N. \& Lioce, L. (2014). Creating effective simulation environments. In B. Ulrich \& B. Mancini, (Eds.). Mastering Simulation: A Handbook for Success (pp. 49-86). Indianapolis, IN: Sigma Theta Tau International.

Jeffries, P. R. (2005). A framework for designing, implementing, and evaluating simulations used as teaching strategies in nursing. Nursing Education Perspectives, 26(2), 96-103.

Issenberg, B. S., Mcgaghie, W. C., Petrusa, E. R., Gordon, D. L., \& Scalese, R. J. (2005). Features and uses of high-fidelity medical simulations that lead to effective learning: a BEME systematic review. Medical Teacher, 27(1), 10-28.

$\mathrm{Li}, \mathrm{S}$. (2007). The role of simulation in nursing education: A regulatory perspective. Retrieved from https://www.ncsbn.org/The_Role)of_Simulation_in_Nursing_Education(1).pdf

Robinson, B.K., \& Dearmon, V. (2013). Evidence-based nursing education: Effective use of instructional design and simulated learning environments to enhance knowledge transfer in undergraduate nursing students.

Schmutz, J., Eppich, W. J., Hoffmann, F., Heimberg, E., and Manser, T. (2014). Five Steps to Develop Checklists for Evaluating Clinical Performance: An Integrative Approach, Academic Medicine.

Waxman, K.T. (2010). The development of evidence based clinical simulation scenarios: guidelines for nurse educators. Journal of Nursing Education, 49(1), 25-35. doi:10.3928/01484834-200909

Zendejas, B., Brydges, R., Wang, R.T., Cook, D.A. (2013). Patient Outcomes in Simulation-Based Medical Education: A Systematic Review. Journal of General Internal Medicine, 28(8), 1078.

\section{GUIDELINE REFERENCES \& SUPPORTING MATERIALS \\ Criterion 1. Needs assessment}

Alinier, G. (2011). Developing high-fidelity health care simulation scenarios: A guide for educators and professionals. Simulation \& Gaming, 42(1), 9-26.

Anderson, J.M.; Aylor, M.E.; Leonard, D.T. (2008). Instructional design dogma: Creating planned learning experiences in simulation. Journal of Critical Care, 23, 595-602.

Robinson, B.K., \& Dearmon, V. (2013). Evidence-based nursing education: Effective use of instructional design and simulated learning environments to enhance knowledge transfer in undergraduate nursing students. Journal of Professional Nursing, 29(4), 203-209.

\section{Criterion 2. Measurable Objectives}

Arthur, C., Levett-Jones,T. \& Kable, A,. (2012). Quality indicators for the design and implementation of simulation experiences: A Delphi study. Nurse Education Today, 33, 1357-1361.

Baker, A.C., Jensen, P.J. \& Kolb, D.A. (2005). Conversation as experiential learning. Management Learning, 36(4), 411-427.

Brewer, E. P. (2011). Successful techniques for using human patient simulation in nursing education. Journal of Nursing Scholarship, 43(3), 311-317. 
Edmondson, A.C. (2002). Managing the risk of learning: Psychological safety in work teams. Blackwell, London, England.

Gore, T. N. \& Lioce, L. (2014). Creating effective simulation environments. In B. Ulrich \& B. Mancini, (Eds.). Mastering Simulation: A Handbook for Success (pp. 49-86). Indianapolis, IN: Sigma Theta Tau International.

Kolb, A.Y. \& Kolb, D.A. (2005). Learning styles and learning spaces: Enhancing experiential learning in higher education. Academy of Management Learning \& Education, 4(2), 193-212.

Lioce, L., Reed, C. C., Lemon, D., King, M. A., Martinez, P. A., Franklin, A. E., Boese, T., Decker, S., Sando, C. R., Gloe, D., Meakim, C., \& Borum, J. C. (2013). Standards of Best Practice: Simulation Standard III: Participant Objectives. Clinical Simulation in Nursing, 9(6S), S15-S18. http://dx.doi.org/10.1016/j.ecns.2013.04.005.

Nembhard, I.M. \& Edmondson, A.C. (2006). Making It Safe: The Effects of Leader Inclusiveness and Professional Status on Psychological Safety and Improvement Efforts in Health Care Teams. Journal of Organizational Behavior, 27(7), 941-966.

Rosen, M.A., Salas, E., Silvestri, S., Wu, T.S., \& Lazzara, E.H. (2008). A measurement tool for simulation-based training in emergency medicine: the simulation module for assessment of resident targeted event responses (SMARTER) approach. Simulation in Healthcare, 3(3), 170-179.

\section{Criterion 3. Format of Simulation}

Alinier, G. (2007). A typology of educationally focused medical simulation tools. Medical Teacher 29(8):e243 - e250.

Bronander, K. (2011). Modalities of simulation. Retrieved from http://www.medicine.nevada.edu/ofd/documents/IPEWorkshopModalities1.pdf

Childs, J.C., Sepples, S.B. and Chambers, K. (2007). Designing simulations for nursing education. In P. R. Jeffries (Ed.), Null [null] (First ed., pp. 35-41). New York, NY: National League for Nursing.

Cook, D. A., Hamstra, S. J., Brydges, R., Zendejas, B., Szostek, J. H., Wang, A. T., . . Hatala, R. (2013). Comparative effectiveness of instructional design features in simulation-based education: Systematic review and meta-analysis. Medical Teacher, 35, e867-e898.

Dieckmann, P., Lippert, A., and Rall, M., \& Glavin, R. (2010). When things don't go as expected: Scenario lifesavers. Simulation in Healthcare, 5(4), 219-225.

Horn, M. \& Carter, N. (2007). Practical suggestions for implementing simulations. In P. R. Jeffries (Ed.), Simulation in nursing education: From conceptualization to evaluation (First ed., pp. 59-72). New York, NY: National League for Nursing.

Jeffries, P. R. (2012). Simulation in nursing education: From conceptualization to evaluation (2nd ed.). Philadelphia, PA: Lippincott Williams \& Wilkins.

Jeffries, P.R. \& Rogers, K.J. (2007). Theoretical framework for simulation design. In P. R. Jeffries (Ed.), Simulation in nursing education: From conceptualization to evaluation (First ed., pp. 21-33). New York, NY: National League for Nursing.

Jeffries, P. R. (2005). A framework for designing, implementing, and evaluating simulations used as teaching strategies in nursing. Nursing Education Perspectives, 26(2), 96-103.

Kaakinen, J. \& Arwood, E. (2009). Systematic review of nursing simulation literature for use of learning theory. International Journal of Nursing Education Scholarship, 6(1), Article 16.

Melny-k, B.M. (2013, June). From simulations to real world: Improving healthcare and patient outcomes with evidence-based practice. Paper presented at the $12^{\text {th }}$ Annual International Nursing Simulation/ Learning Resource Centers Conference, Las Vegas, Nevada.

Rodgers, D. (2013). How simulation works: Learning theory and simulation. 13th Annual International Meeting on Simulation in Healthcare (IMSH), Orlando, FL. 
Rourke, L., \& Schmidt, M. \& Garga, N. (2010). Theory-based research of high-fidelity simulation use in nursing education: A review of the literature. International Journal of Nursing Education Scholarship, 7(1), 1548-923X. doi:10.2202/1548-923X.1965

Schaefer, J. Vanderbilt, A., Cason, C., Bauman, E., Glavin, R., Lee, F., \& Navedo, D. (2011). Literature Review: Instructional design and pedagogy science in healthcare simulation. Simulation in Healthcare, 6(7), S30-S41.

\section{Criterion 4. Clinical Scenario or Case}

Alinier, G. (2007). A typology of educationally focused medical simulation tools. Medical Teacher 29(8):e243 - e250.

Blazeck, A., \& Zewe, G. (2013). Simulating simulation: Promoting perfect practice with learning Bundle Supported videos in an applied, learner-driven curriculum design. Clinical Simulation in Nursing. 9(1), e21-e24.

Maran, N. J., \& Glavin, R. J. (2003). Low-to high-fidelity simulation-a continuum of medical education? Medical education, 37(s1), 22-28.

Rosen, M.A., Salas, E., Silvestri, S., Wu, T.S., \& Lazzara, E.H. (2008). A measurement tool for simulation-based training in emergency medicine: the simulation module for assessment of resident targeted event responses (SMARTER) approach. Simulation in Healthcare, 3(3), 170-179.

Waxman K. (2010). The Development of Evidence-Based Clinical Simulation Scenarios: Guidelines for Nurse Educators. Journal of Nursing Education, 49(1), 29-35. doi: 10.3928/01484834-2009091607.

\section{Criterion 5. Fidelity}

Dieckmann, P., Gaba, D., \& Rall, M. (2007). Deepening the theoretical foundations of patient simulation as social practice. Simulation in Healthcare, 2(3), 183-193.

Edmondson, A. (1999). Psychological safety and learning behavior in work teams. Administrative science quarterly, 44(2), 350-383.

Edmondson, A. C. (2002). Managing the risk of learning: Psychological safety in work teams. Division of Research, Harvard Business School.

Gore, T. N. \& Lioce, L. (2014). Creating effective simulation environments. In B. Ulrich \& B. Mancini, (Eds.). Mastering Simulation: A Handbook for Success (pp. 49-86). Indianapolis, IN: Sigma Theta Tau International.

Nanji, K. C., Baca, K., \& Raemer, D. B. (2013). The Effect of an Olfactory and Visual Cue on Realism and Engagement in a Health Care Simulation Experience. Simulation in Healthcare, 8(3), 143-147.

Nembhard, I. M., \& Edmondson, A. C. (2011). Making it safe: The effects of leader inclusiveness and professional status on psychological safety and improvement efforts in health care teams. In Elaborating Professionalism (pp. 77-105). Springer Netherlands.

Rudolph, J. W., Simon, R., \& Raemer, D. B. (2007). Which reality matters? Questions on the path to high engagement in healthcare simulation. Simulation in Healthcare, 2(3), 161-163.

\section{Criterion 6. Facilitative approach}

Alinier, G. (2011). Developing high-fidelity health care simulation scenarios: A guide for educators and professionals. Simulation \& Gaming, 42(1), 9-26.

Boese, T., Cato, M., Gonzalez, L., Jones, A., Kennedy, K., Reese, C., Decker, S., Franklin, A. E., Gloe, D., Lioce, L., Meakim, C., Sando, C. R., \& Borum, J. C. (2013). Standards of Best Practice: Simulation: Standard V: Facilitator. Clinical Simulation in Nursing, 9(6S), S22-S25. http://dx.doi.org/10.1016/j.ecns.2013.04.010. 
Clapper, T. C. (2010). Beyond Knowles: What those conducting simulation need to know about adult learning theory. Clinical Simulation in Nursing, 6(1), e7-e14.

Franklin, A. E., Boese, T., Gloe, D., Lioce, L., Decker, S., Sando, C. R., Meakim, C., \& Borum, J. C. (2013, June). Standards of Best Practice: Simulation Standard IV: Facilitation. Clinical Simulation in Nursing, 9(6S), S19-S21. http://dx.doi.org/10.1016/j.ecns.2013.04.011.

Hayden, J.K., Smiley, R.A., Alexander, M., Kardong-Edgren, S., \& Jeffries, P.R. (2014). The national simulation study: A longitudinal, randomized, controlled study replacing clinical hours with simulation in prelicensure nursing education. Journal of Nursing Regulation, 5(2S).

\section{Criterion 7. Briefing}

Alinier, G. (2011). Developing high-fidelity health care simulation scenarios: A guide for educators and professionals. Simulation \& Gaming, 42(1), 9-26. . doi: 10.1177/1046878109355683

Bruce, S.A., Scherer, Y.K., Curran, C.C., Urschel, D.M., Erdley, S., \& Ball, L.S. (2009). A collaborative exercise between graduate and undergraduate nursing students using a computer-assisted simulator in a mock cardiac arrest. Nursing Education Perspectives, 30, 22-27.

Deckers, C. (2011). Designing high fidelity simulation to maximize student registered nursing decisionmaking ability (Unpublished doctoral dissertation). Pepperdine University, Malibu, CA.

Decker, S., Fey, M., Sideras, S., Caballero, S., Rockstraw, L. (R.), Boese, T., Franklin, A. E., Gloe, D., Lioce, L., Sando, C. R., Meakim, C., \& Borum, J. C. (2013). Standards of Best Practice: Simulation Standard VI: The debriefing process. Clinical Simulation in Nursing, 9(6S), S27-S29. http://dx.doi.org/10.1016/j.ecns.2013.04.008.

Eggenberger, T., Keller, K., \& Locsin, R.C. (2010). Valuing caring behaviors within simulated emergent nursing situations. International Journal for Human Caring, 14(2), 23-29.

Fanning, R., \& Gaba, D.M. (2007). The role of debriefing in simulation-based learning. Simulation in Healthcare, 2, 115-125.

Gaba, D.M. (2013). Simulations that are challenging to the psyche of participants: How much should we worry and about what? Journal of the Society for Simulation in Healthcare, 8, 4-7. doi:10.1097/ SIH.0b013e3182845a6f

Hermanns, M., Lilly, M.L., \& Crawley, B. (2011). Using clinical simulation to enhance psychiatric nursing training of baccalaureate students. Clinical Simulation in Nursing, 7, e41-e46. doi:10.1016/j.ecns.2010.05.001

Husebo, S.E., Friberg, F., Soreide, E., \& Rystedt, H. (2012). Instructional problems in briefings: How to prepare nursing students for simulation-based cardiopulmonary resuscitation training. Clinical Simulation in Nursing, 8, e307-e318.

Kember, D. (1997). A reconceptualisation of the research into university academics' conceptions of teaching. Learning and Instruction, 7(3), 255-275. doi: http://dx.doi.org/10.1016/S09594752(96)00028-X

Lioce, L., Reed, C. C., Lemon, D., King, M. A., Martinez, P. A., Franklin, A. E., Boese, T., Decker, S., Sando, C. R., Gloe, D., Meakim, C., \& Borum, J. C. (2013). Standards of Best Practice: Simulation Standard III: Participant Objectives. Clinical Simulation in Nursing, 9(6S), S15-S18. http://dx.doi.org/10.1016/j.ecns.2013.04.005

Meakim, C., Boese, T., Decker, S., Franklin, A. E., Gloe, D., Lioce, L., Sando, C. R., \& Borum, J. C. (2013). Standards of Best Practice: Simulation Standard I: Terminology. Clinical Simulation in Nursing, 9(6S), S3-S11. http://dx.doi.org/10.1016/j.ecns.2013.04.001

Page-Cutrara, K. (2014) Use of prebriefing in nursing simulation: A literature review. Journal of Nursing Education, 53.

Riley, R.H. (Ed.). (2008). Manual of simulation in healthcare. New York, NY: Oxford University Press. 
Rudolph, J. W., Simon, R., Dufresne, R. L., \& Raemer, D. B. (2006). There's No Such Thing as "Nonjudgmental" Debriefing: A Theory and Method for Debriefing with Good Judgment. Simulation in Healthcare, 1(1), 49-55.

\section{Criterion 8. Debriefing}

Ahmed, M., Sevdalis, N., Paige, J., Paragi-Gururaja, R., Nestel, D., \& Arora, S. (2012). Identifying best practice guidelines for debriefing in surgery: A tri-continental study. The American Journal of Surgery, 203(4), 523-529.

Decker, S., Fey, M., Sideras, S., Caballero, S., Rockstraw, L. (R.), Boese, T., Franklin, A. E., Gloe, D., Lioce, L., Sando, C. R., Meakim, C., \& Borum, J. C. (2013). Standards of Best Practice: Simulation Standard VI: The debriefing process. Clinical Simulation in Nursing, 9(6S), S27-S29. http://dx.doi.org/10.1016/j.ecns.2013.04.008.

Dieckmann, P., Friss, S. M., Lippert, A., \& Ostergaard, D. (2009). The art and science of debriefing in simulaiton: Ideal and practice. Medical Teacher, 31, e287-e294.

Dismukes, R. K., Gaba, D. M., \& Howard, S. K. (2006). So many roads: Facilitated debriefing in healthcare. Simulation in Healthcare: The Journal of the Society for Medical Simulation, 1(1), 2325.

Fey, M. K., Scrandis, D., Daniels, A., \& Haut, C. (2014). Learning Through Debriefing: Students' Perspectives. Clinical Simulation in Nursing, 10(5), e249-e256.

Raemer, D., Anderson, M., Cheng, A., Fanning, R., Nadkarni, V., \& Savoldelli, G. (2011). Research regarding debriefing as part of the learning process. Simulation in Healthcare: The Journal of the Society for Medical Simulation, 6(S), S52-7.

\section{Criterion 9. Evaluation}

Arthur, C., Levett-Jones,T. \& Kable, A,. (2012). Quality indicators for the design and implementation of simulation experiences: A Delphi study. Nurse Education Today, 33. 1357-1361.

Bambini, D.,Washburn, J. \& Perkins, R. (2009). Outcomes of clinical simulation for novice nursing students: Communication, confidence, clinical judgment. Nursing Education Perspectives, 30(2). 79-82. doi: http://dx.doi.org/10.1043/1536-5026-030.002.0079

Brewer, E. P. (2011). Successful techniques for using human patient simulation in nursing education. Journal of Nursing Scholarship. 43(3), 311-317.

Lioce, L., Reed, C. C., Lemon, D., King, M. A., Martinez, P. A., Franklin, A. E., Boese, T., Decker, S., Sando, C. R., Gloe, D., Meakim, C., \& Borum, J. C. (2013). Standards of Best Practice: Simulation Standard III: Participant Objectives. Clinical Simulation in Nursing, 9(6S), S15-S18. http://dx.doi.org/10.1016/j.ecns.2013.04.005.

Motolo, I., Devine, L.A., Chung, H. S., Sullivan, J. \& Issenberg, S.B. (2013). Simulation in healthcare education: A best evidence practical guide. AMEE Guide No. 82. Medical Teacher. E1511-1524. doi:10.3109/0142159X.2013.818632

Sando, C. R., Coggins, R. M., Meakim, C., Franklin, A. E., Gloe, D., Boese, T., Decker, S., Lioce, L., \& Borum, J. C. (2013). Standards of Best Practice: Simulation Standard VII: Participant Assessment and Evaluation. Clinical Simulation in Nursing, 9(6S), S30-S32. http://dx.doi.org/10.1016/j.ecns.2013.04.007.

Willhaus, J., Burleson, G., Palaganas, J., Jeffries, P., (2014). Authoring Simulations for High-Stakes Student Evaluation, Clinical Simulation in Nursing, 10(4), e177.

\section{Criterion 10. Participant preparation}

Alinier, G. (2011). Developing high-fidelity health care simulation scenarios: A guide for educators and professionals. Simulation \& Gaming, 42(1), 9-26. 
Gloe, D., Sando, C. R., Franklin, A. E., Boese, T., Decker, S., Lioce, L., Meakim, C., \& Borum, J. C. (2013). Standards of Best Practice: Simulation Standard II: Professional Integrity of Participant(s). Clinical Simulation in Nursing, 9(6S), S12-S14. http://dx.doi.org/10.1016/j.ecns.2013.04.004

Jeffries, P. R. (2005). A framework for designing, implementing, and evaluating simulations used as teaching strategies in nursing. Nursing Education Perspectives, 26(2), 96-103.

Zendejas B, Cook DA, Farley DR (2010). Teaching first or teaching last: Does the timing matter in simulation-based surgical scenarios? Journal of Surgical Education, 67(6), 432-438. doi:10.1016/j.jsurg.2010.05.001

\section{Criteria 11: Templates}

Alinier, G. (2011). Developing high-fidelity health care simulation scenarios: A guide for educators and professionals. Simulation \& Gaming, 42(1), 9-26. doi: 10.1177/1046878109355683

Meakim, C.H. \& Mariani, B. (2013, April). Simulation Design Template. Tool presented at one day workshop for staff educators. Designing and Debriefing: Critical Tools for Effective Simulation. Kennedy Health System, Voorhees, NJ.

National League for Nursing. (2010). Simulation Design Template. Retrieved from http://sirc.nln.org/videos/module05/Simulation-Form.pdf

Waxman K.(2010). The Development of Evidence-Based Clinical Simulation Scenarios: Guidelines for Nurse Educators. Journal of Nursing Education, 49(1) 29-35. doi: 10.3928/01484834-20090916-07 


\section{Terminology}

Needs Assessment: A systematic process of identifying gaps in knowledge, skills, or attitudes of the learner. This leads to the purpose of the simulation-based experience. Simulation provides an educational method for the identified learning needs to be achieved. (Bastable, S. (2008). Nurse as educator. Boston: Jones and Bartlett Publishers, 96-97.)

Prebriefing (Briefing) An information or orientation session held prior to the start of a simulation-based experience in which instructions or preparatory information is given to the participants. The purpose of the prebriefing is to set the stage for a scenario and assist participants in achieving scenario objectives. Suggested activities in a prebriefing include an orientation to the equipment, environment, mannequin, roles, time allotment, objectives, and patient situation. INACSL Standards of Best Practice (SOBP): Standard I: Terminology. (2013).

Backstory: A narrative which provides a history and/or background, and is created for a fictional character(s) or about a situation for a SBE. (www.dictionary.com)

Briefing: Briefing is the sharing of information about objectives, time frame, expectations, scenario/case, roles, and type of evaluation with the participants prior to the start of the SBE. (Nehring, W. \& Lashley, F. (2010). High-fidelity patient simulation in nursing education. Boston: Jones and Bartlett Publishers, 331. And Forrest, K., McKimm, J., \& Edgar, S. (2013). Essential simulation in clinical education. Hoboken, NJ: Wiley-Blackwell, 221-222.

Fiction contract: a fiction contract is the implicit or explicit agreement among participants and facilitator(s) about how the participant is expected to interact with the simulated situation and how the facilitators will treat that interaction. (Dieckmann P, Gaba D, Rall M: Deepening the theoretical foundations of patient simulation as social practice. Simulation in Healthcare 2:183-193, 2007).

Frame(s): The perspectives through which individuals interpret new information and experiences for the purpose of decision making. Frames are formed through previous experiences and can be based on knowledge, attitudes, feelings, goals, rules, and/or perceptions; the internal participant or facilitator mindset; knowledge, thoughts, feelings, actions (speech/body language), attitudes (verbal/non-verbal), and perceptions. (adapted from Rudolph, J.W. et al., Debriefing with good judgment: combining rigorous feedback with genuine inquiry. Anesthesiol Clin 25 (2), 361-376 (2007) and Schon, D. A. (1983). The reflective practitioner: How professionals think in action (1st ed.) Basic Books, Inc.

Conceptual Fidelity: Ensures that all elements of the scenario or case relate to each other in a realistic way so that the case makes sense as a whole to the learner(s) (e.g. vital signs are consistent with the diagnosis). To maximize conceptual fidelity, cases or scenarios should be reviewed by subject matter expert(s) and pilot-tested prior to use with learners.

Modality: The way in which something is experienced. In a SBE, it refers to the type of simulation approach, which best meets the objectives. It is not about the tool used per se, but how it is used. www.vocabulary.com

Simulation modality: The means or mode in which a simulated experience is carried out. Computer based simulation- a simulation-based learning activity designed to provide an experience through the use of a computer and screen. Learners can complete specific tasks in a variety of potential environments, use information to provide assessment and care, make clinical decisions and observe the results in action. Feedback can be provided during and after the interaction. (Fowler-Durham, C. \& Alden, K. ( 2008). Chapter 51. Enhancing patient safety in nursing education through patient simulation. Agency for Healthcare Quality and Research. Retrieved from: http://www.ahrq.gov/professionals/cliniciansproviders/resources/nursing/resources/nurseshdbk/durhamc_epsne.pdf) Durham, C. and Alden, K. Enhancing Patient Safety in Nursing Education Through Patient Simulation, Chapter 51 in Patient Safety and Quality: An Evidence-Based Handbook for Nurses. 
AHRQ Publication No. 08-0043, April 2008. Agency for Healthcare Research and Quality, Rockville, MD.http://www.ahrq.gov/qual/nurseshdbk/docs/DurhamC_EPSNE.pdf

Virtual Reality- a computer generated reality, which allows a learner or group of leaners to experience various auditory and visual stimuli. This reality can be experienced through the use of specialized ear and eyewear. (Strategies for Nurse Managers.com. (2014). Simulation learning modalities. Going beyond the basics. Retrieved from:

http://www.strategiesfornursemanagers.com/content.cfm?content_id=243687\&oc_id=602)

Hybrid simulation - a blend of two or more different modes or forms of simulation.

Procedural simulation- the use of a simulation modality (e.g. task trainer, mannequin, computer) to assist in the process of learning to complete a technical skill(s) or a procedure, which is a series of steps taken to accomplish an end.

Simulated clinical immersion- a planned simulated experience in which participants have the experience of being engrossed in a task or setting as they would if it were the real world. The goal of clinical immersion is to evoke or replicate substantial aspects of the real world in a fully interactive fashion. (Stanford School of Medicine (2014). What is ISL? Retreived from: http://cisl.stanford.edu/resources/what_is/)

Standardized Patient (or Simulated Patient)- from current INACSL terminology A person trained to consistently portray a patient or other individual in a scripted scenario for the purposes of instruction, practice, or evaluation (Robinson-Smith, Bradley, \& Meakim, 2009).

Cues: add "aka prompts" 